\title{
Public health nursing education viewed through the lens of superdiversity: a resource for global health
}

\author{
Cécile-Marie Dupin ${ }^{1,2^{*}} \mathbb{D}$, Mélanie Pinon ${ }^{1}$, Karine Jaggi ${ }^{1}$, Celina Teixera ${ }^{1}$, Aurèle Sagne ${ }^{1}$ and Noelia Delicado ${ }^{1}$
}

\begin{abstract}
Background: Nurses are increasingly confronted with the challenge of globalization and the acceleration of migratory flows. This reality affects the notion of culture and its influence on health-related behaviors. The state of health of the population in the Canton of Geneva, where there is a wide diversity of origins, is characterized by significant differences. The term "superdiversity" is used to describe the increasing complexity in ethnic diversity due to migration and social stratification. Nursing education in Geneva, influenced by the Bologna Process, appears appropriate for superdiverse contexts of care, with the development of dedicated competencies.
\end{abstract}

Aim: This discussion paper aims to examine the academic curricula implemented in Geneva in the light of the concept of superdiversity.

Main text: In Geneva, nursing education and curricula in public health are based on a competence framework for nursing care divided into 7 roles and educational tracks. Bachelor's-level nurses know how to assess a care problem quickly and solve it effectively by setting relevant priorities, and do so based on evidence. The curricula aim to teach nurses to design population and individual interventions in their superdiverse context.

Discussion: Education should enable students to develop their role as health promoters for the well-being of patients and communities, taking into account cultural complexity.

Conclusions: Superdiverse contexts highlight the role of nurse educators in preparing future generations of public health nurses.

Keywords: Bologna process, Competencies, Diversity, Global Health, Nursing curricula

\section{Background}

From vocational to academic nursing programs

The nursing profession has experienced fundamental transitions and transformations over the past 50 years. Faced with the health care needs of the twenty-first century [7], it is difficult to see how nurses could develop essential skills (providing patient-centered care, working

\footnotetext{
* Correspondence: cecile.dupin@univ-amu.fr

'Geneva School of Health Sciences, HES-SO University of Applied Sciences and Arts Western Switzerland, Avenue de Champel 42, Geneva, Switzerland ${ }^{2}$ Faculty of Medical and Nursing Science, Aix-Marseille University, Faculté des Sciences Médicales et Paramédicales, 27 BVD Jean Moulin, 13005 Marseille, France
}

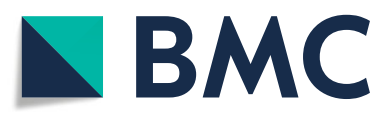

( The Author(s). 2020 Open Access This article is licensed under a Creative Commons Attribution 4.0 International License, which permits use, sharing, adaptation, distribution and reproduction in any medium or format, as long as you give appropriate credit to the original author(s) and the source, provide a link to the Creative Commons licence, and indicate if changes were made. The images or other third party material in this article are included in the article's Creative Commons licence, unless indicated otherwise in a credit line to the material. If material is not included in the article's Creative Commons licence and your intended use is not permitted by statutory regulation or exceeds the permitted use, you will need to obtain permission directly from the copyright holder. To view a copy of this licence, visit http://creativecommons.org/licenses/by/4.0/. The Creative Commons Public Domain Dedication waiver (http://creativecommons.org/publicdomain/zero/1.0/) applies to the data made available in this article, unless otherwise stated in a credit line to the data.

in interdisciplinary teams, improving the quality of continuous care, using information systems, and evidencebased practice) without the benefit of university education [21]. Amid the academic evolution of nursing in Europe, the Bologna Process aims to harmonize higher education by converging towards a common European system, in which different national systems share Bachelor's, Master's, and Doctorate degrees [29, 30, 34]. Historically, European higher education was reserved for the upper classes and had no place for schools of nursing. Previously, nurses were typically trained at the vocational level and obtained their education at institutions other than higher 
education entities [6]. Switzerland is one such European country, where nursing education has only recently begun to evolve from vocational education into undergraduate and graduate education, aided by the Bologna Process. Such transitions aim to facilitate the integration of scientific knowledge into clinical practice, an approach known as Evidence-Based Practice (EBP). The premise of EBP is that rather than focusing their practice solely on traditions and knowledge, professionals should seek information rooted in scientific development $[19,20]$. Similarly, Evidence-Based Nursing (EBN) is a concept that embraces not only research results, but also all other sources of clinical knowledge (expertise, intuition, clinical insight, and perspicacity), as well as patient preferences, in order to make informed decisions [8].

\section{The public health perspective in nursing education}

Public and community health share a common objective: improving the health status of individuals, collectively rather than individually [28]. Today, the increase in social and territorial health inequalities and lifestyle changes, and their consequences on the health status of populations, call for actions on environments, living environments, and the social determinants of health (SDH), achieved through intersectoral and participatory programs [28]. Action and research for population intervention planning must take into account $\mathrm{SDH}$, which offers a wealth of factors to inform decision-making in health promotion. Research conducted in the field of nursing must contribute to the production of useful and usable knowledge $[12,13]$, particularly through intervention research, in order to evaluate existing strategies and contribute to improving the health of populations $[25,26]$. In addition, empowerment strategies for communities targeted by health promotion actions must influence the conditions in which people are born, grow, live, work, and age [33].

Nursing education's transition to higher education has made nurses better-prepared for their future roles, enabling them having a positive impact on the health of individuals and populations in terms of health promotion.

\section{Main text}

\section{Globalization in public health: diversity and disparity} Global health

Study, research, and practice into global health places a priority on improving health and achieving equity in health for all people worldwide [17]. Global health emphasizes transnational health issues, determinants, and solutions; it involves many disciplines within and beyond the health sciences; it promotes interdisciplinary collaboration; and is a synthesis of population-based prevention with individual-level clinical care [17]. Diversity stemming from migration is one of Switzerland's key characteristics, notably in Geneva Canton. In 2017, this urban canton was home to almost 500,000 people, making it the sixthlargest canton in Switzerland in terms of population - one that grew by $6.9 \%$ between 2012 and 2017), in no small part due to migration. In $2017,62.5 \%$ of the population consisted of migrants, compared to $37.2 \%$ for Switzerland as a whole [31]. This diversity stemming from migratory movement is a source of enrichment, but also contributes to the existence of health, social, and economic disparities in Geneva Canton (see Table 1).

\section{The concept of superdiversity}

The scientific literature explores the cultural problems encountered by these populations, their state of health, and their means of access to care [27]. The concept of "superdiversity" relates to the differential convergence of factors surrounding patterns of immigration arising from the complex interplays between newcomers' experiences, opportunities, constraints, and trajectories, and the wider set of social and economic relations within the places where they reside. Such factors include: country of origin (comprising a variety of possible subset traits such as ethnicity, language[s], religious tradition, regional and local identities, cultural values and practices), migration channel (often related to highly gendered flows and specific social networks), legal status (determining entitlement to rights), migrants' human capital

\begin{tabular}{|c|c|c|c|}
\hline \multirow[t]{2}{*}{ Health indicators } & \multirow{2}{*}{$\begin{array}{l}\text { Migratory } \\
\text { status }\end{array}$} & \multirow{2}{*}{$\begin{array}{l}\text { Geneva } \\
\%\end{array}$} & \multirow{2}{*}{$\begin{array}{l}\text { Switzerland } \\
\%\end{array}$} \\
\hline & & & \\
\hline \multirow{2}{*}{$\begin{array}{l}\text { Proportion of individuals } \\
\text { with a (very) good self- } \\
\text { assessed state of health }\end{array}$} & Non-immigrant & 84.7 & 86.7 \\
\hline & $\begin{array}{l}\text { 1st \& 2nd gen. } \\
\text { Immigrants }\end{array}$ & 82.7 & 83.1 \\
\hline \multirow{2}{*}{$\begin{array}{l}\text { Proportion of individuals } \\
\text { with serious limitations in } \\
\text { activities usual for others }\end{array}$} & Non-immigrant & 5.3 & 4.1 \\
\hline & $\begin{array}{l}\text { 1st \& 2nd gen. } \\
\text { Immigrants }\end{array}$ & 5.6 & 4.3 \\
\hline \multirow{2}{*}{$\begin{array}{l}\text { Proportion of individuals } \\
\text { with symptoms of } \\
\text { depression }\end{array}$} & Non-immigrant & 12.2 & 6.7 \\
\hline & $\begin{array}{l}\text { 1st \& 2nd gen. } \\
\text { Immigrants }\end{array}$ & 13.5 & 11.8 \\
\hline \multirow{2}{*}{$\begin{array}{l}\text { Proportion of individuals } \\
\text { with poor social support }\end{array}$} & Non-immigrant & 9.7 & 7.9 \\
\hline & $\begin{array}{l}\text { 1st \& 2nd gen. } \\
\text { Immigrants }\end{array}$ & 14.7 & 13.7 \\
\hline \multirow{2}{*}{$\begin{array}{l}\text { Individuals affected by } \\
\text { pollution at work }\end{array}$} & Non-immigrant & 42.5 & 47 \\
\hline & $\begin{array}{l}\text { 1st \& 2nd gen. } \\
\text { Immigrants }\end{array}$ & 54.2 & 50.5 \\
\hline \multirow{2}{*}{$\begin{array}{l}\text { Proportion of individuals } \\
\text { suffering from physical } \\
\text { stress at work (painful or } \\
\text { tiring postures, lifting or } \\
\text { moving heavy loads, } \\
\text { lifting or moving persons) }\end{array}$} & Non-immigrant & 12.2 & 13.3 \\
\hline & $\begin{array}{l}\text { 1st \& 2nd gen. } \\
\text { Immigrants }\end{array}$ & 19.5 & 22.1 \\
\hline \multirow{2}{*}{$\begin{array}{l}\text { Proportion of individuals } \\
\text { suffering from emotional } \\
\text { fatigue at work (burnout) }\end{array}$} & Non-immigrant & 20.6 & 17.6 \\
\hline & $\begin{array}{l}\text { 1st \& 2nd gen. } \\
\text { Immigrants }\end{array}$ & 24.3 & 21.9 \\
\hline
\end{tabular}


(particularly educational background), access to employment (which may or may not be available to immigrants), locality (related especially to material conditions, but also the nature and extent of other immigrant and ethnic minority presence), transnationalism (emphasizing how migrants' lives are lived with significant reference to places and peoples elsewhere) and the frequently uneven responses by local authorities, service providers, and local residents (which often tend to function by way of assumptions based on previous experiences with migrants and ethnic minorities) [32, 35].

Superdiversity offers a fresh and innovative way of understanding local levels of disparity nested in the challenges of contemporary global health, and appears to be a promising lens through which to analyze public health nursing education.

\section{The need for a fresh perspective on disparity and diversity in $\mathbf{2 0 2 0}$}

While diversity is not a new concept in nursing, further integration of cultural diversity in educational systems and curriculum design for nursing education can positively influence how future nurses integrate the characteristics of superdiverse contexts in their practices.

\section{The new Swiss community health education system}

Since the promulgation of the Bologna Process, a number of different strategies have been adopted by individual countries, the European Union, governments, and professions in order to achieve the outcomes established by the Bologna Declaration. At country level, new policies to change the educational framework, or create the conditions for a new one, have been determined by individual governments responsible for higher education systems, individual universities, and professional associations and networks [22]. In Switzerland, the HES-SO (Hautes Ecoles de Santé Romande, western Switzerland's applied science university network) provides an education that prepares students for professional activities requiring the application of scientific knowledge and methods, for the first cycle of studies: the Bachelor's degree corresponds to 180 credits in the European Credits Transfer System (ECTS). With nine different courses and 3814 students, the HESSO's Health Department is the largest health university in Switzerland and the only one to offer the entire University of Applied Sciences (UAS) syllabus for health. For Geneva, the Best Practice KFH [1] provides a systematic list of competences targeted by the Bachelor's degree in nursing. The competences covered by the Nursing Framework Curriculum express the knowledge and know-how that a specialist must possess to accomplish his or her main tasks. This definition of "competence" uses the terminology of the Copenhagen process (an EU project for the creation of a European vocational training area), which provides a framework for competence models. In this terminology, a "competence" refers to the ability to apply knowledge, know-how and interpersonal skills in a regular or new job. This ability is defined in terms of purpose, autonomy, sense of initiative, responsibilities, relational context, resource use, and profile requirements for a person with a Bachelor's degree in nursing. Each competence has four elements: (1) Cognitive competence, which involves the use of theories/concepts and tacit knowledge gained through experience; (2) Functional competence, which implies a mastery of the skills and know-how necessary to perform a practical function; (3) Personal competence, which implies the ability to know how to behave in a given situation or in a specific professional situation; (4) Ethical competence, which implies reference to certain personal and social values.

Professionals from a UAS background are called upon to deal with problematic, complex, and hard-to-predict situations. Their professional interventions call simultaneously on specialized knowledge and varied methods of action for interventions that are inherently singular, since they are intended for human beings [10]. Bachelor's nurses mobilize their skills, knowledge and professional attitude to provide supportive, preventive, therapeutic, palliative, and educational care oriented towards the person, family, or community. Bachelor's-level nurses know how to quickly grasp a care problem and solve it effectively by setting relevant priorities, and do so based on evidence, whilst observing professional ethics [11].

The Swiss community nursing education aims to educate nurses in critical thinking as well as enabling them to act with the highest degree of professionalism.

\section{Future challenges for public health nursing education}

Information and Communications Technology (ICT) plays a role in nursing student education, improving practices and adjusting them more appropriately to the challenges faced by professionals. However, for nursing, rather than investing in more technology and education, institutions and departments should aim to give more recognition, and respond better, to academics' specific discipline-related needs, so as to reflect the practical realities of nursing education. This constitutes a challenge to traditional teaching models [23].

The Geneva context, characterized in particular by growing health inequalities and diversity, requires dedicated education about how to act on the environment and SDH, intersectoral (transversal) actions, and design participatory programs [14]. This relates to the advancement of knowledge about promising modes of action, $\mathrm{SDH}$, and the development of strategies for their evaluation [9]. Health literacy refers to the individual's ability to obtain, understand, and use the information required to take the appropriate decisions to remain in good 
health [16]. The concept was originally confined to individuals' ability to read and understand written information, but has now been extended to many other factors affecting an individual's ability to have access to, understand, and use information about health and health services [3]. In Geneva, amid high levels of migration, health literacy levels may reflect the diverse makeup of the Canton's population [2]. Public health interventions may even increase social health inequities, in line with the "inverse prevention law", which states that those in most need of preventive interventions are the least likely to receive them, whereas interventions should be of greater benefit to disadvantaged groups [18].

Public health nursing education faces a twofold challenge: educating nurses using appropriate teaching strategies in view of their professional specifics, and designing population and individual interventions for superdiverse contexts.

\section{Superdiversity and health-promoting nursing}

The curricula provided by the HES-SO Health courses is relevant to society because it addresses the present and future health needs of the population and is adapted to the Swiss health system [11] (15). In Geneva, nursing education is based on a competence framework for nursing care, divided into 7 roles and tracks: content derived from scientific knowledge (disciplinary and contributory): nursing science, health sciences, human sciences, research (processes and methods); professional content: methods, approaches and tools of the profession, clinical skills; practical clinical periods: 6 periods of practical education; and a Bachelor's dissertation that contributes to the integration of research results into professional practice. Community health education should enable students to become health promoters - and ensure that as health promoters, nurses use their expertise and influence to promote the health and well-being of patients and communities. The dimensions of the role of health promoter (or at least its significant aspects) include: health promotion, health education, prevention, and quality of life (individual-group-community). Today, the holistic nature of community practice and the diversity of practice learning environments provide students with opportunities to develop a range of skills for contemporary community nursing [4].

Academic curricula must enable nurses to meet these challenges and play this role to the full, as is already acknowledged in various countries, developing 1) public health/community health competences, 2) research competences, and 3) clinical nursing competences [5].

\section{Conclusions}

Superdiversity demonstrates that cultural change does not occur overnight: it occurs over years and generations.
Cross-cultural values are needed in a cross-cultural world, and nurse educators will need to lead the way in preparing future generations of international nurses [6]. Crosscultural research among nurse educators is limited [15], but important: nurse educators are on the front line when it comes to educating the next generation of nurses [24].

\section{Abbreviations}

EBN: Evidence-Based Nursing; EBP: Evidence-Based Practice; ECTS: European Credits Transfer System; ICT: Information and Communications Technology; SDH: Social Determinants of Health; UAS: University of Applied Sciences

\section{Acknowledgements}

We would like to thank David and Naomi Buick for support with language revision.

\section{Authors' contributions}

CMD was responsible for paper inception and design, and drafting the initial and final manuscript. MP, KJ, AS, CT and ND added intellectual content. All authors read and approved the final manuscript.

\section{Funding}

The University of Applied Sciences and Arts Western Switzerland supported CMD and ND for this study.

\section{Availability of data and materials}

Data sharing is not applicable to this article as no datasets were generated or analyzed during the current study.

Ethics approval and consent to participate

Not applicable.

\section{Consent for publication}

Not applicable.

\section{Competing interests}

The authors declare that they have no competing interests.

Received: 4 November 2019 Accepted: 5 March 2020

\section{(-}

\section{References}

1. Project for the Final Competencies for Health Professions in the Universities of Applied Sciences. Annual report of the Rector's conference of the Swiss Universities of Applied Sciences. Bern. 2011. Accès: 11.2019: https://www. swissuniversities.ch/fileadmin/swissuniversities/Dokumente/Kammern/ Kammer_FH/Best_practice/1_Competences_finales_pour_les_professions_ de la sante HES rapport final.pdf.

2. Balcou-Debussche M, Rogers C. Promoting health education in a context of strong social and cultural heterogeneity: the case of Reunion Island. In: Simovska V, McNamara PM, editors. Schools for Health and Sustainability. Dordrecht: Springer; 2015. p. 291-312. https://doi.org/10.1007/978-94-0179171-7_14.

3. Batterham RW, Hawkins M, Collins PA, Buchbinder R, Osborne RH. Health literacy: applying current concepts to improve health services and reduce health inequalities. Public Health. 2016;132:3-12. https://doi.org/10.1016/j. puhe.2016.01.001.

4. Cable C, Dickson C, Morris G. Inspiring undergraduates towards a career in community nursing: Clare Cable and colleagues look at what must be done to create evidence-based models for placements that go beyond traditional clinical areas. Nurs Manag. 2015;22(6):18-25. https://doi.org/10.7748/nm.22.6. 18.e1382.

5. Clark M, Raffray M, Hendricks K, Gagnon AJ. Global and public health core competencies for nursing education: a systematic review of essential competencies. Nurse Educ Today. 2016;40:173-80. https://doi.org/10.1016/j. nedt.2016.02.026.

6. Collins S, Hewer I. The impact of the Bologna process on nursing higher education in Europe: a review. Int J Nurs Stud. 2014;51(1):150-6. https://doi. org/10.1016/j.jijnurstu.2013.07.005. 
7. Committee on the Robert Wood Johnson Foundation Initiative on the Future of Nursing, at the Institute of Medicine, \& Institute of Medicine. The future of nursing: Leading change, advancing health. Washington,DC: National Academies Press; 2011. https://doi.org/10.17226/12956.

8. DiCenso A, Guyatt G, Cliska D. Evidence-based nursing: A guide to clinical practice (Elsevier Health Sciences). London: Mosby, Inc; 2005.

9. Dupin CM, Breton E, Kivits J, Minary L. Pistes de réflexion pour l'évaluation et le financement des interventions complexes en santé publique. Santé Publique. 2015;27(5):653-7.

10. Framework for Bachelor education in Nursing. (2012). University of Applied Sciences of Western Switzerland.

11. General directorate for health, Division of the cantonal doctor. (2017). Republic and canton of Geneva.

12. Hallberg IR. Moving nursing research forward towards a stronger impact on health care practice? Int J Nurs Stud. 2009;46(4):407-12. https://doi.org/10. 1016/j.jijnurstu.2009.02.005.

13. Hallberg IR. Challenges for the future nursing research: Providing evidence for health-care practice. Int J Nurs Stud. 2006;43:923-7. https://doi.org/10. 1016/j.jijnurstu.2006.07.017.

14. Hawe P, Potvin L. What is population health intervention research? Can J Public Health. 2009;100(1):8-14.

15. Jackson C, Bell L, Zabalegui A, Palese A, Sigurðardóttir ÁK, Owen S. A review of nurse educator career pathways; a European perspective. J Res Nurs. 2009;14(2):111-22. https://doi.org/10.1177/1744987108102084.

16. Kickbusch I, Pelikan J. In: Tsouros A, editor. Health Literacy. The Solid Facts. Copenhaguen: World Health Organization; 2013.

17. Koplan JP, Bond TC, Merson MH, Reddy KS, Rodriguez MH, Sewankambo NK, Wasserheit JN. Towards a common definition of global health. Lancet. 2009;373(9679):1993-5. https://doi.org/10.1016/S0140-6736(09)60332-9.

18. Lorenc T, Petticrew M, Welch V, Tugwell P. What types of interventions generate inequalities? Evidence from systematic reviews. J Epidemiol Community Health. 2012;67(2):190-3. https://doi.org/10.1136/jech-2012201257

19. Melnyk BM, Gallagher-Ford L, Long LE, Fineout-Overholt E. The establishment of evidence-based practice competencies for practicing registered nurses and advanced practice nurses in real-world clinical settings: proficiencies to improve healthcare quality, reliability, patient outcomes, and costs: EBP competencies for practice. Worldviews Evid-Based Nurs. 2014;11(1):5-15. https://doi.org/10.1111/wvn.12021.

20. Newhouse RP. Creating infrastructure supportive of evidence-based nursing practice: leadership strategies. Worldviews Evid-Based Nurs. 2007:4(1):21-9. https://doi.org/10.1111/j.1741-6787.2007.00075.x.

21. Norman I. Nursing must be a graduate profession (well, he would say that wouldn't he!). Int J Nurs Stud. 2014;51(4):523-5. https://doi.org/10.1016/j. ijnurstu.2014.01.004.

22. Palese A, Zabalegui A, Sigurdardottir AK, Bergin M, Dobrowolska B, Gasser C, Pajnkihar M, Jackson C. Bologna process, more or less: nursing education in the European economic area: a discussion paper. Int J Nurs Educ Scholarsh. 2014;11(1). https://doi.org/10.1515/ijnes-2013-0022.

23. Petit dit Dariel OJ, Raby T, Ravaut F, Rothan-Tondeur M. Developing the serious games potential in nursing education. Nurse Educ Today. 2013; 33(12):1569-75. https://doi.org/10.1016/j.nedt.2012.12.014.

24. Råholm M-B, Hedegaard BL, Löfmark A, Slettebø A. Nursing education in Denmark, Finland, Norway and Sweden - from Bachelor's degree to PhD: nursing education in Scandinavian countries. J Adv Nurs, no-no. 2010. https://doi.org/10.1111/j.1365-2648.2010.05331.x.

25. Richards DA, Coulthard V, Borglin G, on behalf of the REFLECTION review team. The state of European nursing research: dead, alive, or chronically diseased? A systematic literature review: reviewing the state of European nursing research. Worldviews Evid-Based Nurs. 2014;11(3):147-55. https:// doi.org/10.1111/wvn.12039.

26. Richards DA, Hanssen TA, Borglin G. The second triennial systematic literature review of European nursing research: impact on patient outcomes and implications for evidence-based practice. Worldviews Evid-Based Nurs. 2018;15(5):333-43. https://doi.org/10.1111/wvn.12320

27. Ruiz-Casares M, Rousseau C, Laurin-Lamothe A, Rummens JA, Zelkowitz P, Crépeau F, Steinmetz N. Access to health care for undocumented migrant children and pregnant women: the paradox between values and attitudes of health care professionals. Matern Child Health J. 2013;17(2):292-8. https:// doi.org/10.1007/s10995-012-0973-3.
28. Solar, O., \& Irwin, A. (Eds.). (2007). A Conceptual Framework for Action on the Social Determinants of Health. \& Commission on the Social Determinants of Health.

29. Spitzer A, Perrenoud B. Reforms in nursing education across Western Europe: from agenda to practice. J Prof Nurs. 2006a;22(3):150-61. https://doi. org/10.1016/j.profnurs.2006.03.003.

30. Spitzer A, Perrenoud B. Reforms in nursing education across Western Europe: implementation processes and current status. J Prof Nurs. 2006b; 22(3):162-71. https://doi.org/10.1016/j.profnurs.2006.03.011.

31. Swiss Health Observatory (2019). Health in Geneva Canton. Final Report.

32. Vertovec S. Super-diversity and its implications. Ethn Racial Stud. 2007;30(6): 1024-54. https://doi.org/10.1080/01419870701599465.

33. World Health Organization. (2010). A conceptual framework for action on the social determinants of health: Debates, policy \& practice, case studies. http://apps.who.int/iris/bitstream/10665/44489/1/9789241500852_eng.pdf.

34. Zabalegui A, Macia L, Marquez J, Ricoma R, Nuin C, Mariscal I, Pedraz A, German C, Moncho J. Changes in nursing education in the European Union. J Nurs Scholarsh. 2006;38(2):114-8. https://doi.org/10.1111/j.1547-5069.2006. 00087.x.

35. Zeeb H, Makarova N, Brand T, Knecht M. Superdiversity - a new concept for migrant health? Public Health Forum. 2015;23(2). https://doi.org/10.1515/ pubhef-2015-0045.

\section{Publisher's Note}

Springer Nature remains neutral with regard to jurisdictional claims in published maps and institutional affiliations.
Ready to submit your research? Choose BMC and benefit from:

- fast, convenient online submission

- thorough peer review by experienced researchers in your field

- rapid publication on acceptance

- support for research data, including large and complex data types

- gold Open Access which fosters wider collaboration and increased citations

- maximum visibility for your research: over $100 \mathrm{M}$ website views per year

At BMC, research is always in progress.

Learn more biomedcentral.com/submissions 